OPEN ACCESS

Edited by:

Barbara Zavan,

Università degli Studi di Padova, Italy

Reviewed by: Federica Barbieri,

Università di Genova, Italy Elisabetta Rovida,

Università degli Studi di Firenze, Italy Deepak Gurbani,

University of Texas Southwestern Medical Center, United States

*Correspondence:

Triantafyllos Stylianopoulos tstylian@ucy.ac.cy

Specialty section:

This article was submitted to Molecular and Cellular Oncology, a section of the journal Frontiers in Oncology

Received: 01 December 2017 Accepted: 20 February 2018 Published: 12 March 2018

Citation: Kalli M and Stylianopoulos T (2018) Defining the Role of Solid Stress and Matrix Stiffness in Cancer Cell Proliferation and Metastasis.

Front. Oncol. 8:55. doi: 10.3389/fonc. 2018.00055

\section{Defining the Role of Solid Stress and Matrix Stiffness in Cancer Cell Proliferation and Metastasis}

\author{
Maria Kalli and Triantafyllos Stylianopoulos* \\ Cancer Biophysics Laboratory, Department of Mechanical and Manufacturing Engineering, University of Cyprus, \\ Nicosia, Cyprus
}

Solid tumors are characterized by an abnormal stroma that contributes to the development of biomechanical abnormalities in the tumor microenvironment. In particular, these abnormalities include an increase in matrix stiffness and an accumulation of solid stress in the tumor interior. So far, it is not clearly defined whether matrix stiffness and solid stress are strongly related to each other or they have distinct roles in tumor progression. Moreover, while the effects of stiffness on tumor progression are extensively studied compared to the contribution of solid stress, it is important to ascertain the biological outcomes of both abnormalities in tumorigenesis and metastasis. In this review, we discuss how each of these parameters is evolved during tumor growth and how these parameters are influenced by each other. We further review the effects of matrix stiffness and solid stress on the proliferative and metastatic potential of cancer and stromal cells and summarize the in vitro experimental setups that have been designed to study the individual contribution of these parameters.

Keywords: extracellular matrix, fibroblasts, externally applied stress, growth-induced stress, in vitro models

\section{UNRAVELING THE TUMOR MICROENVIRONMENT}

Tumor stroma and biomechanical abnormalities developed during tumor growth comprise dominant regulators of cancer progression (1-3). The tumor stroma is composed of an extracellular matrix (ECM), which consists of immune cells, fibroblasts, capillaries, and fibrillar proteins, such as collagen I, elastin, and fibronectin, as well as hyaluronan and other sulfated glycosaminoglycans (4). Fibroblasts are key regulators of ECM composition and organization and physiologically remain in the quiescent state with negligible metabolic and transcriptomic activities $(5,6)$. In response to tissue damage, fibroblasts become activated and are characterized by the expression of alpha-smooth muscle actin ( $\alpha$-SMA). In this activated state, fibroblasts overproduce ECM proteins, mainly collagen I and fibronectin, secrete cytokines and growth factors, and exert contractile forces modifying tissue architecture $(5,6)$.

In tumors, fibroblasts tend to acquire a constantly activated phenotype as a response to several growth factors secreted from the highly proliferative cancer cells, including transforming growth factor- $\beta$ (TGF $\beta$ ), epidermal growth factors (EGFs), and bone morphogenetic proteins (BMPs) (5, 6). Activated fibroblasts, which are commonly known as cancer-associated fibroblasts (CAFs), start a chronic wound healing-like response toward cancer cells, leading to an excessive accumulation of fibrillar ECM proteins, a condition known as desmoplasia (5). Under this desmoplastic reaction, CAFs continuously produce and remodel the tumor ECM increasing tumor stiffness $(1,5)$. Desmoplasia and ECM stiffening characterize many tumor types, especially breast and pancreatic cancers, and it usually promotes tumor progression $(1,7,8)$. 
As the density of cancer cells, stromal cells, and ECM constituents increase within the restricted environment of the host tissue, it leads to the development of mechanical stress (i.e., force per unit area) within the tumor $(1,3,9-11)$. This stress, derived from the structural components of a tumor, is known as solid stress and can be divided into two parts. A part of it, known as growthinduced (or residual) stress, is accumulated during tumor growth by microscopic interactions among structural components of the tumor microenvironment, and it remains within the tumor even if the tumor is removed (3). These interactions might include collagen stretching by cancer cells and CAFs, and hyaluronan and cancer cell swelling to resist compression (12-15). Moreover, as tumors grow and exert forces on the adjacent host tissue, a reciprocal compressive stress is applied from the host tissue to the tumor, to resist tumor expansion (1). This stress is known as externally applied stress, and it diminishes after tumor excision (1). The total solid stress in a tumor interior is compressive (i.e., tends to reduce the size of an object), while near the interface between the tumor and normal tissue, the stress is tensile (i.e., tends to increase the size of an object) $(16,17)$.

\section{THE DEFINITION OF ECM STIFFNESS AND SOLID STRESS}

It is not clearly defined in the pertinent literature whether matrix stiffness and solid stress refer to the same term or they are two distinct biomechanical abnormalities of a tumor that are related to each other. By definition, stiffness is a material property, which describes the extent to which a material resists deformation in response to an applied force, while solid stress is a force per unit area, which can cause either compaction (compression) or expansion (tension) of a material. In solid tumors, the stiffness is mainly determined by ECM composition and organization, while solid stress arises by the sum of the physical forces exerted during tumor growth. These forces can be generated in the subcellular level by cytoskeletal filaments that control cellular processes such as filopodia formation and extension. At the cellular level, forces are exerted by cell contractions (such as in CAFs) and cell-ECM interactions during migration of cancer and stromal cells, while at the tissue level, forces are exerted between the tumor and the host tissue (18-21).

The relationship between tumor stiffness and solid stress can be described using the analogy of a spring of specific elastic modulus (E) that obeys Hooke's law (Figure 1). According to the equation of Hooke's law for linear elastic materials, $\sigma=E \cdot \varepsilon$, when a tumor of elastic modulus $\mathrm{E}$ grows and pushes the surrounding host tissue of elastic modulus $\mathrm{E}^{\prime}$, it causes a deformation $\varepsilon_{1}$ and a subsequent stress $\sigma_{1}$. As a consequence, the host tissue returns an equal and opposite stress $\sigma_{1}{ }^{\prime}$, the so-called externally applied solid stress. At the same time, growth-induced solid stress is accumulated in the tumor interior owing to interactions among tumor components (Figure 1A). Thus, the total solid stress accumulated intratumorally is the sum of the externally applied and the growth-induced solid stress. In the case that the stiffness of the tumor $E_{2}$ is greater than $E_{1}$, then the tumor can displace the host tissue with a greater deformation and the externally applied solid stress $\sigma_{2}$ can be greater than $\sigma_{1}$ (Figure 1B). Therefore, in

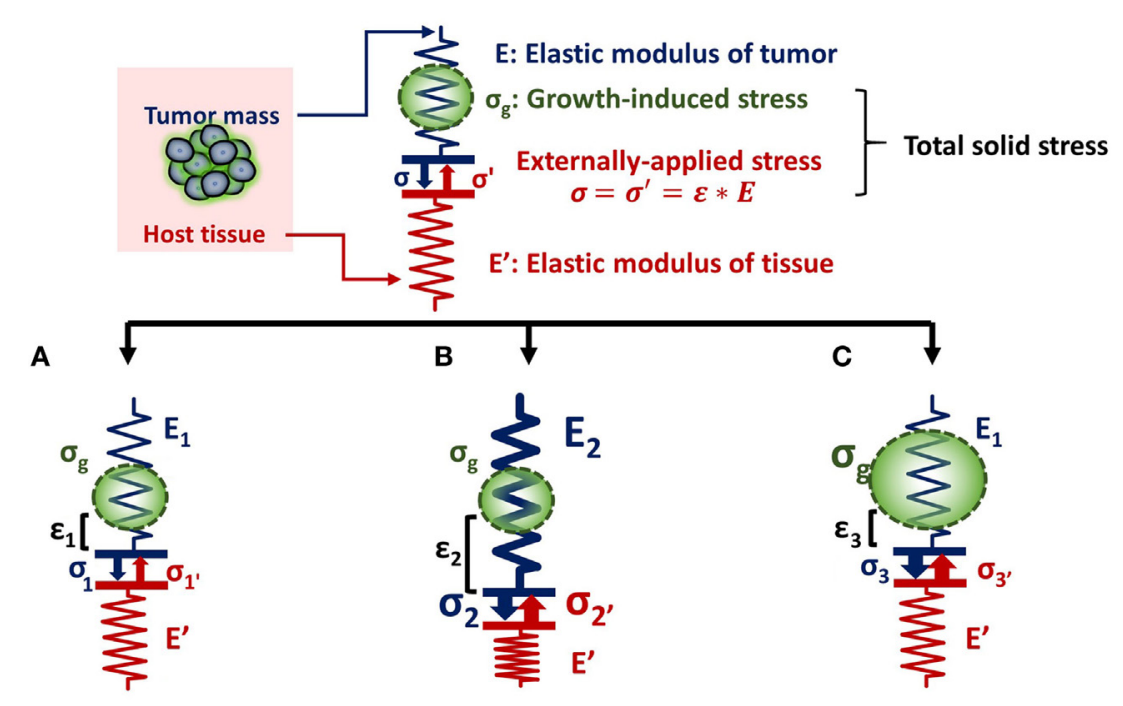

FIGURE 1 | Solid stress and stiffness are two distinct biomechanical abnormalities present in the tumor microenvironment. (A) According to the simple analogy of a spring that obeys Hooke's law $\sigma=\mathrm{E} \cdot \varepsilon$, when a tumor grows and pushes the surrounding host tissue of elastic modulus $\mathrm{E}^{\prime}$, it results in a deformation $\varepsilon_{1}$ and a stress, $\sigma_{1}$. As a consequence, the host tissue returns an equal and opposite stress $\sigma_{1}{ }^{\prime}$, which is defined as externally applied solid stress $\left(\sigma_{1}=\sigma_{1}{ }^{\prime}\right)$. This externally applied stress, in combination with the growth-induced stress $\left(\sigma_{g}\right)$, generated from mechanical interactions within the tumor, constitutes the total solid stress transmitted in the tumor interior. (B) In the case that the tumor stiffens so that $E_{2}$ is greater than $E_{1}\left(E_{2}>E_{1}\right)$, the tumor can increase in size and the deformation $\varepsilon_{2}$ is greater than $\varepsilon_{1}\left(\varepsilon_{2}>\varepsilon_{1}\right)$. The externally applied stress $\left(\sigma_{2}{ }^{\prime}\right)$ and finally the total solid stress accumulated in the tumor interior are greater than that in (A) without any change in the growth-induced stress. (C) The growth-induced solid stress, however, increases during growth, while tumor stiffening might remain the same (16). In this case, the externally applied solid stress $\sigma_{3}{ }^{\prime}$ can be equal to $\sigma_{1}{ }^{\prime}$, but total solid stress increases. Therefore, the resultant stress transmitted in the tumor interior is greater than that in (A) without any change in tumor stiffness. 
this case, a solid tumor creates a stiffer matrix to push against the normal tissue and grow in size. Indeed, it has been demonstrated using mathematical modeling that the stiffness of a solid tumor should be at least 1.5 times greater than that of the host tissue, in order for the tumor to displace the tissue and grow (14).

As for the growth-induced solid stress, it increases during tumor growth, while the matrix stiffness might stop changing (16, 17). In this case, the further increase in total solid stress accumulated intratumorally can become less depended on matrix stiffness (Figure 1C). This hypothesis was confirmed by an elegant study by Nia et al. (16), showing that the total solid stress transmitted into the cells can depend only in part on tumor stiffness, and thus, the two terms should not be used without a distinction. Specifically, Nia et al. found that primary pancreatic tumors exhibited larger stresses compared to those in metastatic sites, while the opposite effect was observed for colon tumors (16). Interestingly, tumor stiffness was similar in the primary and metastatic tumor for both the pancreatic and colon cancer models, showing that tumor stiffness and solid stress are not necessarily coupled to each other. In addition, they found that solid stress increased in breast tumors of larger size despite the fact that stiffness did not change with tumor size. In line with our analysis, these observations can be explained by the fact that growth-induced solid stress generated owing to microscopic interactions among structural components in the tumor interior contributes to the accumulation of an additional to the externally applied solid stress. Therefore, the effects of matrix stiffness and solid stress on tumorigenesis and metastasis should be studied separately (22). Following, we provide a summary of these effects on cancer and stromal cell behavior, elaborating on the less studied contribution of solid stress and the pertinent experimental setups.

\section{EFFECTS OF MATRIX STIFFNESS ON CANCER AND STROMAL CELLS}

The effect of ECM stiffness on cancer and stromal cells has been studied using in vitro two-dimensional substrates (2D) and threedimensional tumor analogs (3D). In 2D models, cells are seeded on coating substrates such as collagen or fibronectin (23-26), while the 3D models include single cells or tumor spheroids embedded in gels composed of collagen or matrigel (27-34) (Figure 2A). In both cases, stiffness is increased by changing the protein density or the degree of crosslinking of the matrix to study the effects of ECM-originating mechanical cues on cancer and stromal cells.

Matrix stiffness can activate intracellular signaling pathways to regulate cellular behavior. Cancer cells recognize the increase in ECM stiffness and respond by generating increased traction forces on their surroundings through actomyosin and cytoskeleton contractility $(9,35,36)$. Moreover, the changes in matrix rigidity are sensed and transmitted intracellularly through mechanosensors such as p130 CRK-associated proteins, growth factor receptors, or integrin-ECM adhesion plaques $(9,10,23$, $35,37-40)$. These mechanosensors can recruit focal adhesion molecules such as FAK, SRC, paxillin, RAC, RHO/RAS GTPases, and Rho-associated kinase to trigger signaling cascades and cytoskeleton organization $(9,10,35,36,39,41-44)$. These cascades finally regulate gene expression and induce quantifiable changes in cell shape, survival, migration, and invasion $(9,35$, 39, 42). For example, it has been shown that tissue stiffness activates the nuclear translocation of the transcription factor TWIST1 in breast cancer cells, which inhibits the expression of E-cadherin and promotes cell invasion $(35,45)$. Furthermore, in a $3 \mathrm{D}$ model consisting of breast tumor spheroids growing in collagen matrix, the Ras suppressor-1 (RSU-1), a cell-ECM adhesion protein, was shown to be upregulated as a response to increasing stiffness. Interestingly, tumor spheroids knockdown for RSU-1 or actin polymerization regulator (VASP) lost their invasiveness through the $3 \mathrm{D}$ matrix $(46,47)$. Matrix stiffening is also shown to induce fibroblast activation and migration, which leads to a fibrotic response setting a positive feedback to matrix stiffness $(13,15,35,48,49)$. However, in these studies, it cannot be distinguished explicitly whether the observed effects are emerged by increased cell-ECM adhesion sites owing to increased ECM density or by stiffness-induced solid stress generation.

\section{EFFECTS OF SOLID STRESS ON CANCER AND STROMAL CELLS}

While the role of ECM stiffness in cancer and stromal cells is actively studied, data regarding the effect of solid stress on tumor progression are elusive. There are several experimental setups mimicking the solid stress developed in the tumor microenvironment. These setups include models consisting of tumor spheroids growing in a confined environment that causes the development of solid stress (50-57) and models employing a transmembrane pressure device that applies a mechanical compression on a cell monolayer or on single cells embedded in a matrix $(51,58-60)$ (Figure 2B).

Regarding the first method, cancer cells are grown as spheroids in a polymer gel (e.g., agarose), which leads to the development of solid stress that resists to spheroid expansion (Figure $\mathbf{2 B}, \mathbf{i}$ ). Helmlinger et al. (55) using spheroids of colon adenocarcinoma cells estimated that the accumulated solid stress was in the range of $45-120 \mathrm{mmHg}(6-16 \mathrm{kPa})$, depending on the concentration of the agarose gel and the size of the spheroid. In an analogous study, Cheng et al. (51) estimated the solid stress to be $\sim 28 \mathrm{mmHg}$ $(\sim 3.73 \mathrm{kPa})$ when mammary carcinoma cell spheroids were growing in a $0.5 \%$ agarose matrix. Recent in vivo measurements of breast, colon, pancreatic, and brain tumors estimated that the growth-induced stress is in the range of $1.56-142.4 \mathrm{mmHg}$ $(0.21-20 \mathrm{kPa})(3,11,16,54)$. Differences in the magnitude of solid stress among in vitro studies and between in vitro and in vivo methods should depend on the tumor model and the experimental procedure used in each study. However, the conclusion that increasing compressive stress inhibits tumor growth is common $(51,52,55,57)$, while this effect was reversed when loads were removed $(51,55)$. It was also observed that solid stress can regulate tumor morphology since mechanical loads can induce apoptotic cell death in regions with high compressive stress and allow proliferation in low-stress regions of the tumor spheroid, suggesting that anisotropic loads result in anisotropic tumor growth (51). 

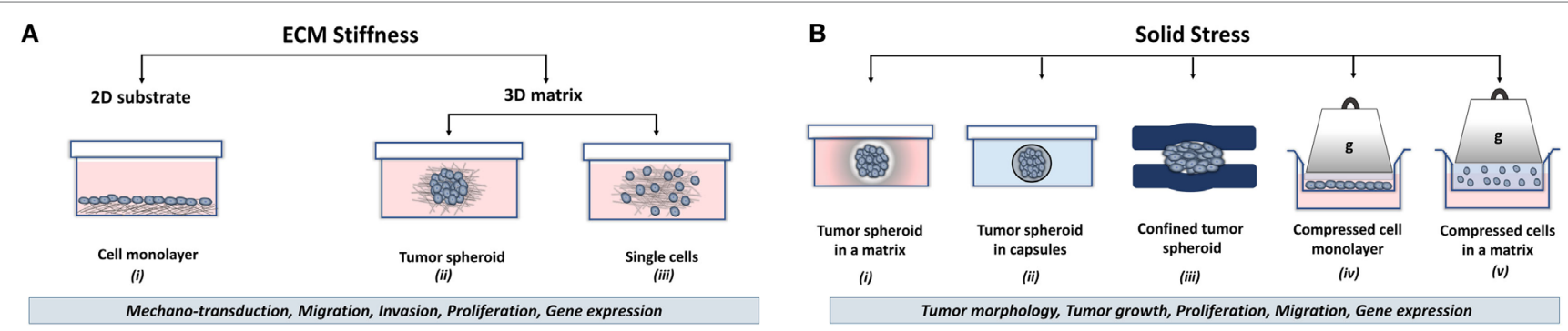

C

\begin{tabular}{|c|c|c|c|c|c|}
\hline \multicolumn{6}{|c|}{ Summary of studies revealing the effect of solid stress in tumor progression } \\
\hline \multirow[t]{2}{*}{ Study } & \multirow[t]{2}{*}{$\begin{array}{l}\text { Experimental } \\
\text { Setup }\end{array}$} & \multirow[t]{2}{*}{ Cancer Model } & \multicolumn{2}{|c|}{ Level of solid stress } & \multirow[t]{2}{*}{ Biological Outcome } \\
\hline & & & Stress Applied & Stress Estimated & \\
\hline Helmlinger G., et al., Nature Biotechnology (1997) & Figure 2B (ii) & $\begin{array}{l}\text { Human colon adenocarcinoma, Murine mammary } \\
\text { carcinoma, Rat rhabdomyosarcoma cancer cells }\end{array}$ & . & $\begin{array}{l}\text { 45-120 mmHg } \\
(6-16 \mathrm{kPa})\end{array}$ & $\begin{array}{c}\text { Estimation of growth-induced solid stress and how it affects } \\
\text { tumor growth }\end{array}$ \\
\hline Mitsui N., et al., Life Sciences (2006) & Figure 2B (iv) & Bone osteosarcoma cancer cells & $\begin{array}{r}0.4-2.2 \mathrm{mmHg} \\
(0.05-0.29 \mathrm{kPa})\end{array}$ & - & Effect of solid stress on gene expression \\
\hline Cheng G., et al., Plos One (2009) & Figure 2B (i), (iv) & Human breast cancer cells & $\begin{array}{c}0-60 \mathrm{mmHg} \\
(0-8 \mathrm{kPa})\end{array}$ & $\begin{array}{c}\sim 28 \mathrm{mmHg} \\
(3.7 \mathrm{kPa})\end{array}$ & $\begin{array}{l}\begin{array}{c}\text { Estimation of growth-induced solid stress and how it affects } \\
\text { tumor growth }\end{array} \\
\text { thor }\end{array}$ \\
\hline Demou Z., Annals of Biomedical Engineering (2010) & Figure 2B (v) & Human brain and breast cancer cells & $\begin{array}{l}0.37-1.87 \mathrm{mmHg} \\
(0.05-0.25 \mathrm{kPa})\end{array}$ & - & Effect of solid stress on gene expression and cell shape \\
\hline Tse J.M., et al., PNAS (2012) & Figure 2B (iv) & Human breast cancer cells & $\begin{array}{l}5.8 \mathrm{mmHg} \\
(0.77 \mathrm{kPa})\end{array}$ & - & Effect of solid stress on cancer cell migration and invasion \\
\hline Stylianopoulos T., et al., PNAS (2012) & $\begin{array}{l}\text { In vivo } \\
\text { (In situ) }\end{array}$ & $\begin{array}{l}\text { Human melanoma, Human glioblastoma, Human } \\
\text { fibrosarcoma, } \\
\text { Human colon and pancreatic adenocarcinoma, } \\
\text { Murine melanoma, pancreatic and mammary } \\
\text { adenocarcinoma }\end{array}$ & - & $\begin{array}{l}1.56 \text { to } 142.2 \mathrm{mmHg} \\
(0.21-20 \mathrm{kPa})\end{array}$ & $\begin{array}{l}\text { Estimation of growth-induced solid stress and how solid stress } \\
\text { affects drug delivery }\end{array}$ \\
\hline Alessandri K., et al., pNAS (2013) & Figure 2B (ii) & Mouse colon carcinoma cells & $\begin{array}{l}15 \mathrm{mmHg} \\
(2 \mathrm{kPa})\end{array}$ & $\begin{array}{l}15 \mathrm{mmHg} \\
(2 \mathrm{kPa})\end{array}$ & $\begin{array}{l}\text { Effect of solid stress on tumor growth and cancer } \\
\text { cell migration }\end{array}$ \\
\hline Desmaison A., et al., Plos One (2013) & Figure 2B (iii) & Human colorectal cancer cells & - & - & Effect of solid stress on tumor growth and cancer cell mitosis \\
\hline Delarue M. et al,, Biophysical J (2014) & Figure 2B (i) & $\begin{array}{l}\text { Human and mouse colon adenocarcinoma cells, Human } \\
\text { breast cancer cells, Mouse sarcoma cells and Murine } \\
\text { Schwann cells }\end{array}$ & $\begin{array}{l}37.5-75 \mathrm{mmHg} \\
(5-10 \mathrm{kPa})\end{array}$ & - & Effect of solid stress on tumor growth and cell proliferation \\
\hline Fernández-Sánchez M.E., et al., Nature (2015) & In vivo & Mouse colon adenocarcinoma & $\begin{array}{l}8.95 \pm 4.95 \mathrm{mmHg} \\
(1.194 \pm 0.660 \mathrm{kPa})\end{array}$ & $\begin{array}{l}0-42 \mathrm{mmHg} \\
(0-5.6 \mathrm{kPa})\end{array}$ & $\begin{array}{l}\text { Effect of solid stress developed by tumor on the adjacent normal } \\
\text { tissue }\end{array}$ \\
\hline Nia H., et al,, Nature Biomedical Engineering (2016) & $\begin{array}{l}\text { In vivo } \\
\text { (in situ) }\end{array}$ & Breast, Pancreatic, Brain cancer models & - & $\begin{array}{l}1.56-52.5 \mathrm{mmHg} \\
(0.21-7 \mathrm{kPa})\end{array}$ & $\begin{array}{l}\text { Estimation of solid stress and its relationship with tumor and/or } \\
\text { tissue stiffness }\end{array}$ \\
\hline Chen Q., et al., Oncogenesis (2017) & Figure 2B (iv) & Renal cell carcinoma & $\begin{array}{c}0.5 \mathrm{mmHg} \\
(0-0.66 \mathrm{kPa})\end{array}$ & - & $\begin{array}{c}\text { Effect of growth-induced solid stress on cancer cell migration and } \\
\text { epithelial-to-mesenchymal transition in combination with } \\
\text { interleukine- } 6 \text { treatment }\end{array}$ \\
\hline Kalli M., et al,, Annals of Biomedical Engineering (2018) & Figure 2B (iv) & Human normal pancreatic fibroblasts & $\begin{array}{c}0-4 \mathrm{mmHg} \\
(0-0.53 \mathrm{KPa})\end{array}$ & - & $\begin{array}{l}\text { Effect of solid stress on normal pancreatic fibroblasts and } \\
\text { pancreatic cancer cell migration }\end{array}$ \\
\hline
\end{tabular}

FIGURE 2 | Experimental methods employed to analyze the effects of stiffness and solid stress on cancer and stromal cells in vitro. (A) Experimental setups studying the effect of ECM stiffness on cancer and stromal cells. There are two-dimensional models (2D) consisting of (i) a cell monolayer seeded on coating substrates (e.g., collagen type I or fibronectin) and three-dimensional models (3D) consisting of (ii) tumor spheroids or (iii) single cells embedded in a matrix (e.g., collagen type I, matrigel). Both models were aimed to investigate the effect of changes in extracellular rigidity on the transduction of mechanical signals into the cells as well as on the migration, invasion, proliferation and gene expression of cancer and stromal cells (B) Experimental setups studying the effect of solid stress on cancer and stromal cells. Setups include tumor spheroids that grow within (i) a polymer matrix, (ii) within elastic capsules, or (iii) in a confined polymer device. (iv,v) The setups are composed of cells seeded on the inner chamber of a transwell insert on the top of which an agarose cushion is placed or are embedded in a polymer matrix. A piston with adjustable weight applies a predefined and measurable compressive solid stress on the cells. These models provided useful information about the direct effect of solid stress on tumor growth and morphology as well as on cancer cell proliferation, migration, and gene expression.

(C) A summary of in vitro and in vivo studies for the effect of solid stress in tumor progression.

More recent studies developed novel techniques to mimic solid stress during tumor growth in the absence of a matrix. Alessandri et al. (50) employed a microfluidic method based on the encapsulation and growth of cells inside permeable, elastic, and hollow microspheres (Figure 2B, ii). This approach offered the ability to produce size-controlled multicellular spheroids growing in confined conditions. They found that the confined spheroids exhibited a necrotic core compared with the unconfined spheroids. In contrast, peripheral cells were more proliferative and migratory, suggesting that mechanical cues from the surrounding microenvironment may trigger cell invasion from a growing tumor (50). Desmaison et al. (53) designed polymer polydimethylsiloxane microdevices to restrict the growth of spheroids and subsequently to induce the development of mechanical stress (Figure 2B, iii). They showed that the mitosis of mechanically confined spheroids was suppressed compared to spheroids grown in suspension (53). Furthermore, it was demonstrated that a population of cells within the confined tumor spheroids was arrested at mitosis, which was due to the inhibition of bipolar spindle assembly (53). Later, Fernández-Sánchez et al. (54) developed a method that allows the delivery of a defined mechanical pressure in vivo by subcutaneously inserting a magnet close to the mouse colon. The implanted magnet generates a magnetic force on ultramagnetic liposomes stabilized in the mesenchymal cells of the connective tissue surrounding colonic crypts after intravenous injection (54). The induced pressure was similar in magnitude to the endogenous stress (54), in the order of $9.0 \mathrm{mmHg}(1.2 \mathrm{kPa})$, without affecting tissue stiffness, as monitored by ultrasound strain imaging and shear wave elastography (54). The magnetic pressure stimulated Ret activation and the subsequent $\beta$-catenin phosphorylation, impairing its interaction with E-cadherin in adherens junctions (54). These data suggested that tumor progression could be driven by signaling pathways that are directly activated by mechanical pressure. 
To study the effect of a predefined solid stress on cancer cells, the transmembrane pressure device has been introduced (Figure 2B, iv). Setups employed consist of a transwell insert that fits in a well of a 6-well culture plate. The insert is separated in the lower chamber containing culture medium and the upper chamber containing the cell monolayer. A piston of a preferable weight is applied on the cell monolayer, while water, nutrients, and oxygen from the culture media are diffused through the pores of the transmembrane. This device provides a tool to mimic solid stress in a predefined manner according to the stress magnitudes measured in native tumor tissues.

Cheng et al. (51) used this device to study the effect of solid stress on murine mammary carcinoma cells. In this study, they applied a stress ranging from 0 to $60 \mathrm{mmHg}(0-8 \mathrm{kPa})$, and they observed increased apoptosis with increased stress levels. In a following study, they used the same experimental setup to study the migration of cancer cells using a scratch wound assay (60). They applied a stress of $5.8 \mathrm{mmHg}(0.77 \mathrm{kPa})$, and concluded that in these levels of compression, cancer cells stopped proliferating and started to create a leader cell formation, which allowed them to move toward the scratch having an invasive phenotype. Mitsui et al. (59) used a similar device for bone osteosarcoma cells to identify the effect of compressive stress on the expression of matrix metalloproteinases and plasminogen activators. They observed enhanced protein and mRNA levels of these molecules under low mechanical compression of bone cells (0-2.20 mmHg/0-0.29 kPa) (59). Recently, Chen et al. (61) observed increased migration and mesenchymal-like phenotype of renal carcinoma cells that were compressed by $0-5.0 \mathrm{mmHg}$ $(0-0.66 \mathrm{kPa})$, while Kalli et al. (62) found that normal fibroblasts become activated as a response to solid stress to promote pancreatic cancer cell migration.

Another device that was developed to study the effect of solid stress in a more realistic way involved the use of single cancer cells growing in an agarose matrix (Figure 2B, v). This device was composed of two custom-made parts, the well pressor and the optic pressor (58). Both devices consisted of a chamber containing a 3D gel with single cells embedded, a screw and a nut for pressure application, and their housing support. Specifically, the well pressor applied a strain that compressed the cell-contained agarose gels to $50 \%$ of their original volume. This stress was estimated to be $\sim 0.37 \mathrm{mmHg}(\sim 0.05 \mathrm{kPa})$, much smaller than loads measured by other studies $(3,51,55,58)$. However, this stress was sufficient to cause differential expression profiles of metastasis-associated genes in glioblastoma and breast cancer cells. In addition, the optic pressor provided quantifiable changes in cell circularity and orientation with respect to the direction of the applied force (58).

Collectively, these in vitro studies suggest that mechanical forces can regulate tumor morphology, tumor growth, and metastatic potential of cancer cells in the absence of matrix stiffness. However, as indicated in Figure 2C, there is a discrepancy among the levels of solid stress applied or estimated in the pertinent studies due to the variability of the experimental procedures and the cancer models used. Therefore, it should be given special attention when performing experiments to study the effect of solid stress on tumor progression, taking into account the estimations derived from in vivo studies.

\section{CONCLUSION AND FUTURE PERSPECTIVES}

In light of recent studies showing that increased matrix stiffness and elevated solid stress are two distinct tumor abnormalities, and given the fact that most pertinent studies are focused on the effects of stiffness, it becomes clear that scientific efforts need to focus on the implications of solid stress in tumor progression and metastasis $(16,22)$.

Regarding the implications of tumor stiffness in tumor progression, most pertinent in vitro models include only cancer cells and ECM matrix. However, tumor stiffness might also depend on the presence of stromal CAFs that continuously interact with the fibrillar proteins. CAFs-ECM interactions remodel the ECM organization and fibers orientation for cancer cells to migrate and invade into the matrix $(1,63,64)$. Regarding the effects of solid stress on tumor progression, further studies are required to shed light upon the mechanisms by which solid stress is transmitted and guides cellular behavior of both cancer cells and CAFs. Moreover, CAFs exert contractile forces that contribute to the accumulation of solid stress in the tumor interior. Therefore, it is necessary to include both cell types when solid stress and ECM stiffness are being studied.

It has been also shown that CAFs dynamically interact with cancer cells to promote tumor progression $(62,64)$. In fact, CAFs mediate the invasiveness of colon, pancreatic, and breast cancer cells when co-injected into mice (64-68), while breast and prostate tumors containing CAFs grew faster than tumors injected with normal fibroblasts $(69,70)$. Nevertheless, there is no pertinent study taking into account the effect of ECM stiffness and solid stress on the interaction of cancer cells and CAFs and vice versa the implication of tumor-stromal interactions in ECM stiffening and solid stress accumulation.

Concerning the complexity of the tumor microenvironment, new experimental setups consisting of cancer cells, CAFs, and changes in matrix stiffness and solid stress, in combination or separately, should be introduced to broaden our knowledge about the role of each component in the evolution and malignancy of cancer.

\section{AUTHOR CONTRIBUTIONS}

MK and TS planned and wrote the manuscript of this mini review.

\section{FUNDING}

This research has received funding from the European Research Council under the European Union's Seventh Framework Programme (FP7/2007-2013)/ERC Grant Agreement No. 336839-ReEngineeringCancer. 


\section{REFERENCES}

1. Jain RK, Martin JD, Stylianopoulos T. The role of mechanical forces in tumor growth and therapy. Annu Rev Biomed Eng (2014) 16:321-46. doi:10.1146/ annurev-bioeng-071813-105259

2. Spill F, Reynolds DS, Kamm RD, Zaman MH. Impact of the physical microenvironment on tumor progression and metastasis. Curr Opin Biotechnol (2016) 40:41-8. doi:10.1016/j.copbio.2016.02.007

3. Stylianopoulos T, Martin JD, Chauhan VP, Jain SR, Diop-Frimpong B, Bardeesy N, et al. Causes, consequences, and remedies for growth-induced solid stress in murine and human tumors. Proc Natl Acad Sci U S A (2012) 109:15101-8. doi:10.1073/pnas.1213353109

4. Quail DF, Joyce JA. Microenvironmental regulation of tumor progression and metastasis. Nat Med (2013) 19:1423-37. doi:10.1038/nm.3394

5. Kalluri R. The biology and function of fibroblasts in cancer. Nat Rev Cancer (2016) 16:582-98. doi:10.1038/nrc.2016.73

6. Kalluri R, Zeisberg M. Fibroblasts in cancer. Nat Rev Cancer (2006) 6:392-401. doi:10.1038/nrc1877

7. Acerbi I, Cassereau L, Dean I, Shi Q, Au A, Park C, et al. Human breast cancer invasion and aggression correlates with ECM stiffening and immune cell infiltration. Integr Biol (Camb) (2015) 7:1120-34. doi:10.1039/c5ib00040h

8. Rath N, Olson MF. Regulation of pancreatic cancer aggressiveness by stromal stiffening. Nat Med (2016) 22:462-3. doi:10.1038/nm.4099

9. Butcher DT, Alliston T, Weaver VM. A tense situation: forcing tumour progression. Nat Rev Cancer (2009) 9:108-22. doi:10.1038/nrc2544

10. Paszek MJ, Weaver VM. The tension mounts: mechanics meets morphogenesis and malignancy. J Mammary Gland Biol Neoplasia (2004) 9:325-42. doi:10.1007/s10911-004-1404-x

11. Voutouri C, Polydorou C, Papageorgis P, Gkretsi V, Stylianopoulos T. Hyaluronan-derived swelling of solid tumors, the contribution of collagen and cancer cells, and implications for cancer therapy. Neoplasia (2016) 18:732-41. doi:10.1016/j.neo.2016.10.001

12. McGrail DJ, McAndrews KM, Brandenburg CP, Ravikumar N, Kieu QM, Dawson MR. Osmotic regulation is required for cancer cell survival under solid stress. Biophys J (2015) 109:1334-7. doi:10.1016/j.bpj.2015.07.046

13. Tomasek JJ, Gabbiani G, Hinz B, Chaponnier C, Brown RA. Myofibroblasts and mechano-regulation of connective tissue remodelling. Nat Rev Mol Cell Biol (2002) 3:349-63. doi:10.1038/nrm809

14. Voutouri C, Mpekris F, Papageorgis P, Odysseos AD, Stylianopoulos T. Role of constitutive behavior and tumor-host mechanical interactions in the state of stress and growth of solid tumors. PLoS One (2014) 9:e104717. doi:10.1371/ journal.pone.0104717

15. Wipff PJ, Rifkin DB, Meister JJ, Hinz B. Myofibroblast contraction activates latent TGF-betal from the extracellular matrix. J Cell Biol (2007) 179:1311-23. doi:10.1083/jcb.200704042

16. Nia HT, Liu H, Seano G, Datta M, Jones D, Rahbari N, et al. Solid stress and elastic energy as measures of tumour mechanopathology. Nat Biomed Eng (2016) 1:0004. doi:10.1038/s41551-016-0004

17. Stylianopoulos T, Martin JD, Snuderl M, Mpekris F, Jain SR, Jain RK. Coevolution of solid stress and interstitial fluid pressure in tumors during progression: implications for vascular collapse. Cancer Res (2013) 73:3833-41. doi:10.1158/0008-5472.CAN-12-4521

18. Chen CS. Mechanotransduction - a field pulling together? J Cell Sci (2008) 121:3285. doi:10.1242/jcs.023507

19. De Pascalis C, Etienne-Manneville S. Single and collective cell migration: the mechanics of adhesions. Mol Biol Cell (2017) 28:1833-46. doi:10.1091/mbc. E17-03-0134

20. Polacheck WJ, Chen CS. Measuring cell-generated forces: a guide to the available tools. Nat Methods (2016) 13:415-23. doi:10.1038/nmeth.3834

21. Stylianopoulos T. The solid mechanics of cancer and strategies for improved therapy. J Biomech Eng (2017) 139(2):021004. doi:10.1115/1.4034991

22. Gilkes DM, Wirtz D. Tumour mechanopathology: cutting the stress out. Nat Biomed Eng (2017) 1:0012. doi:10.1038/s41551-016-0012

23. Friedland JC, Lee MH, Boettiger D. Mechanically activated integrin switch controls alpha5betal function. Science (2009) 323:642-4. doi:10.1126/ science. 1168441

24. Li Z, Dranoff JA, Chan EP, Uemura M, Sévigny J, Wells RG. Transforming growth factor-beta and substrate stiffness regulate portal fibroblast activation in culture. Hepatology (2007) 46:1246-56. doi:10.1002/hep.21792
25. Ulrich TA, de Juan Pardo EM, Kumar S. The mechanical rigidity of the extracellular matrix regulates the structure, motility, and proliferation of glioma cells. Cancer Res (2009) 69:4167-74. doi:10.1158/0008-5472.CAN-08-4859

26. Yeung T, Georges PC, Flanagan LA, Marg B, Ortiz M, Funaki M, et al. Effects of substrate stiffness on cell morphology, cytoskeletal structure, and adhesion. Cell Motil Cytoskeleton (2005) 60:24-34. doi:10.1002/cm.20041

27. Kaufman LJ, Brangwynne CP, Kasza KE, Filippidi E, Gordon VD, Deisboeck TS, et al. Glioma expansion in collagen I matrices: analyzing collagen concentration-dependent growth and motility patterns. Biophys J (2005) 89:635-50. doi:10.1529/biophysj.105.061994

28. Kraning-Rush CM, Reinhart-King CA. Controlling matrix stiffness and topography for the study of tumor cell migration. Cell Adh Migr (2012) 6:274-9. doi:10.4161/cam.21076

29. Mason BN, Starchenko A, Williams RM, Bonassar LJ, Reinhart-King CA. Tuning three-dimensional collagen matrix stiffness independently of collagen concentration modulates endothelial cell behavior. Acta Biomater (2013) 9:4635-44. doi:10.1016/j.actbio.2012.08.007

30. Paszek MJ, Zahir N, Johnson KR, Lakins JN, Rozenberg GI, Gefen A, et al. Tensional homeostasis and the malignant phenotype. Cancer Cell (2005) 8:241-54. doi:10.1016/j.ccr.2005.08.010

31. Pedersen JA, Swartz MA. Mechanobiology in the third dimension. Ann Biomed Eng (2005) 33:1469-90. doi:10.1007/s10439-005-8159-4

32. Szot CS, Buchanan CF, Freeman JW, Rylander MN. 3D in vitro bioengineered tumors based on collagen I hydrogels. Biomaterials (2011) 32:7905-12. doi:10.1016/j.biomaterials.2011.07.001

33. Van Goethem E, Poincloux R, Gauffre F, Maridonneau-Parini I, Le Cabec V. Matrix architecture dictates three-dimensional migration modes of human macrophages: differential involvement of proteases and podosome-like structures. J Immunol (2010) 184:1049-61. doi:10.4049/ jimmunol.0902223

34. Zaman MH, Trapani LM, Sieminski AL, Mackellar D, Gong H, Kamm RD, et al. Migration of tumor cells in 3D matrices is governed by matrix stiffness along with cell-matrix adhesion and proteolysis. Proc Natl Acad Sci U S A (2006) 103:10889-94. doi:10.1073/pnas.0604460103

35. Northey JJ, Przybyla L, Weaver VM. Tissue force programs cell fate and tumor aggression. Cancer Discov (2017) 7:1224-37. doi:10.1158/2159-8290. CD-16-0733

36. Samuel MS, Lopez JI, McGhee EJ, Croft DR, Strachan D, Timpson P, et al. Actomyosin-mediated cellular tension drives increased tissue stiffness and beta-catenin activation to induce epidermal hyperplasia and tumor growth. Cancer Cell (2011) 19:776-91. doi:10.1016/j.ccr.2011.05.008

37. Defilippi P, Di Stefano P, Cabodi S. p130Cas: a versatile scaffold in signaling networks. Trends Cell Biol (2006) 16:257-63. doi:10.1016/j.tcb.2006.03.003

38. Gehler S, Baldassarre M, Lad Y, Leight JL, Wozniak MA, Riching KM, et al. Filamin A-beta1 integrin complex tunes epithelial cell response to matrix tension. Mol Biol Cell (2009) 20:3224-38. doi:10.1091/mbc.E08-12-1186

39. Kharaishvili G, Simkova D, Bouchalova K, Gachechiladze M, Narsia N, Bouchal J. The role of cancer-associated fibroblasts, solid stress and other microenvironmental factors in tumor progression and therapy resistance. Cancer Cell Int (2014) 14:41. doi:10.1186/1475-2867-14-41

40. Levental KR, Yu H, Kass L, Lakins JN, Egeblad M, Erler JT, et al. Matrix crosslinking forces tumor progression by enhancing integrin signaling. Cell (2009) 139:891-906. doi:10.1016/j.cell.2009.10.027

41. Lawson CD, Burridge K. The on-off relationship of Rho and Rac during integrin-mediated adhesion and cell migration. Small GTPases (2014) 5:e27958. doi:10.4161/sgtp.27958

42. Polacheck WJ, Zervantonakis IK, Kamm RD. Tumor cell migration in complex microenvironments. Cell Mol Life Sci (2013) 70:1335-56. doi:10.1007/ s00018-012-1115-1

43. Ross TD, Coon BG, Yun S, Baeyens N, Tanaka K, Ouyang M, et al. Integrins in mechanotransduction. Curr Opin Cell Biol (2013) 25:613-8. doi:10.1016/j. ceb.2013.05.006

44. Shi Q, Boettiger D. A novel mode for integrin-mediated signaling: tethering is required for phosphorylation of FAK Y397. Mol Biol Cell (2003) 14:4306-15. doi:10.1091/mbc.E03-01-0046

45. Wei SC, Fattet L, Tsai JH, Guo Y, Pai VH, Majeski HE, et al. Matrix stiffness drives epithelial-mesenchymal transition and tumour metastasis through a TWIST1-G3BP2 mechanotransduction pathway. Nat Cell Biol (2015) 17:678-88. doi:10.1038/ncb3157 
46. Gkretsi V, Stylianou A, Louca M, Stylianopoulos T. Identification of Ras suppressor-1 (RSU-1) as a potential breast cancer metastasis biomarker using a three-dimensional in vitro approach. Oncotarget (2017) 8:27364-79. doi:10.18632/oncotarget.16062

47. Gkretsi V, Stylianou A, Stylianopoulos T. Vasodilator-stimulated phosphoprotein (VASP) depletion from breast cancer MDA-MB-231 cells inhibits tumor spheroid invasion through downregulation of Migfilin, beta-catenin and urokinase-plasminogen activator (uPA). Exp Cell Res (2017) 352:281-92. doi:10.1016/j.yexcr.2017.02.019

48. Wipff PJ, Hinz B. Myofibroblasts work best under stress. J Bodyw Mov Ther (2009) 13:121-7. doi:10.1016/j.jbmt.2008.04.031

49. Zhang K, Grither WR, Van Hove S, Biswas H, Ponik SM, Eliceiri KW, et al. Mechanical signals regulate and activate SNAIL1 protein to control the fibrogenic response of cancer-associated fibroblasts. J Cell Sci (2016) 129:1989-2002. doi:10.1242/jcs.180539

50. Alessandri K, Sarangi BR, Gurchenkov VV, Sinha B, Kießling TR, Fetler L, et al. Cellular capsules as a tool for multicellular spheroid production and for investigating the mechanics of tumor progression in vitro. Proc Natl Acad Sci U S A (2013) 110:14843-8. doi:10.1073/pnas.1309482110

51. Cheng G, Tse J, Jain RK, Munn LL. Micro-environmental mechanical stress controls tumor spheroid size and morphology by suppressing proliferation and inducing apoptosis in cancer cells. PLoS One (2009) 4:e4632. doi:10.1371/ journal.pone.0004632

52. Delarue M, Montel F, Vignjevic D, Prost J, Joanny JF, Cappello G. Compressive stress inhibits proliferation in tumor spheroids through a volume limitation. Biophys J (2014) 107:1821-8. doi:10.1016/j.bpj.2014.08.031

53. Desmaison A, Frongia C, Grenier K, Ducommun B, Lobjois V. Mechanical stress impairs mitosis progression in multi-cellular tumor spheroids. PLoS One (2013) 8:e80447. doi:10.1371/journal.pone.0080447

54. Fernández-Sánchez ME, Barbier S, Whitehead J, Béalle G, Michel A, LatorreOssa $\mathrm{H}$, et al. Mechanical induction of the tumorigenic $\beta$-catenin pathway by tumour growth pressure. Nature (2015) 523:92. doi:10.1038/nature14329

55. Helmlinger G, Netti PA, Lichtenbeld HC, Melder RJ, Jain RK. Solid stress inhibits the growth of multicellular tumor spheroids. Nat Biotechnol (1997) 15:778-83. doi:10.1038/nbt0897-778

56. Koike C, McKee TD, Pluen A, Ramanujan S, Burton K, Munn LL, et al. Solid stress facilitates spheroid formation: potential involvement of hyaluronan. $\mathrm{Br}$ J Cancer (2002) 86:947-53. doi:10.1038/sj.bjc.6600158

57. Roose T, Netti PA, Munn LL, Boucher Y, Jain RK. Solid stress generated by spheroid growth estimated using a linear poroelasticity model. Microvasc Res (2003) 66:204-12. doi:10.1016/S0026-2862(03)00057-8

58. Demou ZN. Gene expression profiles in $3 \mathrm{D}$ tumor analogs indicate compressive strain differentially enhances metastatic potential. Ann Biomed Eng (2010) 38:3509-20. doi:10.1007/s10439-010-0097-0

59. Mitsui N, Suzuki N, Koyama Y, Yanagisawa M, Otsuka K, Shimizu N, et al. Effect of compressive force on the expression of MMPs, PAs, and their inhibitors in osteoblastic Saos-2 cells. Life Sci (2006) 79:575-83. doi:10.1016/j. lfs.2006.01.040
60. Tse JM, Cheng G, Tyrrell JA, Wilcox-Adelman SA, Boucher Y, Jain RK, et al. Mechanical compression drives cancer cells toward invasive phenotype. Proc Natl Acad Sci U S A (2012) 109:911-6. doi:10.1073/pnas.1118910109

61. Chen Q, Yang D, Zong H, Zhu L, Wang L, Wang X, et al. Growth-induced stress enhances epithelial-mesenchymal transition induced by IL-6 in clear cell renal cell carcinoma via the Akt/GSK-3beta/beta-catenin signaling pathway. Oncogenesis (2017) 6:e375. doi:10.1038/oncsis.2017.74

62. Kalli M, Papageorgis P, Gkretsi V, Stylianopoulos T. Solid stress facilitates fibroblasts activation to promote pancreatic cancer cell migration. Ann Biomed Eng (2018). doi:10.1007/s10439-018-1997-7

63. Egeblad M, Rasch MG, Weaver VM. Dynamic interplay between the collagen scaffold and tumor evolution. Curr Opin Cell Biol (2010) 22:697-706. doi:10.1016/j.ceb.2010.08.015

64. Karagiannis GS, Poutahidis T, Erdman SE, Kirsch R, Riddell RH, Diamandis EP. Cancer-associated fibroblasts drive the progression of metastasis through both paracrine and mechanical pressure on cancer tissue. Mol Cancer Res (2012) 10:1403-18. doi:10.1158/1541-7786.MCR-12-0307

65. Dimanche-Boitrel MT, Vakaet L Jr, Pujuguet P, Chauffert B, Martin MS, Hammann A, et al. In vivo and in vitro invasiveness of a rat colon-cancer cell line maintaining E-cadherin expression: an enhancing role of tumor-associated myofibroblasts. Int J Cancer (1994) 56:512-21. doi:10.1002/ijc.2910560410

66. Hwang RF, Moore T, Arumugam T, Ramachandran V, Amos KD, Rivera A, et al. Cancer-associated stromal fibroblasts promote pancreatic tumor progression. Cancer Res (2008) 68:918-26. doi:10.1158/0008-5472.CAN-07-5714

67. Masamune A, Shimosegawa T. Pancreatic stellate cells: a dynamic player of the intercellular communication in pancreatic cancer. Clin Res Hepatol Gastroenterol (2015) 39(Suppl 1):S98-103. doi:10.1016/j.clinre.2015.05.018

68. Trimis G, Chatzistamou I, Politi K, Kiaris H, Papavassiliou AG. Expression of p21waf1/Cip1 in stromal fibroblasts of primary breast tumors. Hum Mol Genet (2008) 17:3596-600. doi:10.1093/hmg/ddn252

69. Olumi AF, Grossfeld GD, Hayward SW, Carroll PR, Tlsty TD, Cunha GR. Carcinoma-associated fibroblasts direct tumor progression of initiated human prostatic epithelium. Cancer Res (1999) 59:5002-11.

70. Orimo A, Gupta PB, Sgroi DC, Arenzana-Seisdedos F, Delaunay T, Naeem R, et al. Stromal fibroblasts present in invasive human breast carcinomas promote tumor growth and angiogenesis through elevated SDF-1/CXCL12 secretion. Cell (2005) 121:335-48. doi:10.1016/j.cell.2005.02.034

Conflict of Interest Statement: The authors declare that the research was conducted in the absence of any potential conflict of interest.

Copyright () 2018 Kalli and Stylianopoulos. This is an open-access article distributed under the terms of the Creative Commons Attribution License (CC BY). The use, distribution or reproduction in other forums is permitted, provided the original author(s) and the copyright owner are credited and that the original publication in this journal is cited, in accordance with accepted academic practice. No use, distribution or reproduction is permitted which does not comply with these terms. 